\title{
Dose-dependent effect of betamethasone on the articular cartilage (experimental study)
}

\author{
A.N. Nuriakhmetov ${ }^{1,2}$, I.F. Akhtiamov ${ }^{1,2}$, D.E. Tsyplakov ${ }^{1}$, A.M. Abdullah ${ }^{1}$, T.Yu. Nuriakhmetova ${ }^{1}$ \\ ${ }^{1}$ Kazan State Medical University, Kazan, Russian Federation \\ ${ }^{2}$ Republican Clinical Hospital, Kazan, Russian Federation
}

\begin{abstract}
Introduction Glucocorticosteroid injections have been widely used in clinical practice. Betamethasone is one of the agents of this group of drugs. Its efficacy and therapeutic effect with intra-articular administration are undeniable. There are special instructions on the dosage and frequency of use of the drug but unfortunately there are cases of its wrong administration. There is also an evidence of an adverse effect on cartilage both of the drug itself and its combination with local anesthetics. Aim Evaluation of the results of different weekly intraarticular protocols of betamethasone administration on histological preparations of rabbit knee joints. Methods Histological preparations of the right knee joints of three groups of rabbits were studied: after one, three, and six administrations of betamethason per week and the control intact left knee joints. Results Histological preparations of the control group and the group with a single weekly administration of the drug did not have any changes in the structure of diarthrosis. Dystrophic and necrotic changes affecting all morphological components were observed in the joints of animals that received intra-articular injections of betamethason three times a week (compared to a single injection, the area of dystrophy and necrosis of the cartilage was greater by $10.05 \pm 0.75 \%(\mathrm{p}<0.05)$, of subchondral bone by $8.11 \pm 0.5 \%$ $(\mathrm{p}<0.001)$, and of synovium by $6.25 \pm 0.32 \%(\mathrm{p}<0.05)$. The group with six injections of the drug per week had the most pronounced changes. The area of necrotic changes of the cartilage was greater by $6.39 \pm 0.75 \%$ than in the group with three injections per week $(\mathrm{p}<0.001)$, of subchondral bone by $11.18 \pm 0.5 \%(\mathrm{p}<0.001)$, of synovium by $6.12 \pm 0.32 \%(\mathrm{p}<0.001)$. Discussion Inflammatory cell infiltration of joint structures was absent in all cases. It indicates an aseptic nature of tissue necrosis. Evidence has been obtained between the increase in the frequency of intra-articular injections of betamethasone and the severity of dystrophic and necrotic changes in all morphological components of the joint.
\end{abstract}

Keywords: glucocorticosteroids, betamethasone, intra-articular injection

Intra-articular injections of medical drugs play an important role in the complex treatment of patients with joint pathology. The use of this method helps to stabilize the grade of osteoarthritis (OA) and has a positive effect on the state of the articular components. Injections of intra-articular glucocorticosteroids (GCS) reduce pain and secondary inflammation in OA patients, rheumatoid arthritis, and other arthropathies. The method has been widely used in traumatology and orthopedics, rheumatology, and neurology. Betamethasone, a twocomponent synthetic glucocorticosteroid, is one of the drugs for intra-articular therapy. This agent has antiinflammatory, anti-rheumatic, immunosuppressive and anti-allergic properties. The drug is a combination of two salts of betamethasone, betamethasone sodium phosphate (BNP) dissolved in water that provides a fast therapeutic effect (within 2-4 hours after administration), and betamethasone dipropionate (BDP) which is of a prolonged action (4 or more weeks). Betamethasone has certain tribological properties, providing a lubricating effect on the articular surfaces after mixing with the synovial fluid. It should be noted that betamethasone has a high index of anti-inflammatory activity (equal to 30 ) and has a finecrystalline structure (5.3 $\mu \mathrm{m}$ in size $)$, which provides its optimal safety profile. Betamethasone is recommended for such diseases of the musculoskeletal system as OA, rheumatoid arthritis, bursitis, epicondylitis, fasciitis, foot diseases, and some others.

However, the cytotoxic effect of GCSs on the cartilage tissue has been reported in combination with local anesthetics [1]. J.L. Dragoo et al [2] revealed a significant decrease in the viability of chondrocytes on days 9 and 14 after a single injection of $1 \mathrm{mg}$ BNP betamethasone acetate (BA), despite the cultivation of chondrocytes using a constant infusion pump to create the effect of intra-articular fluid metabolism.

In their recent study, M.A. Kabalyk et al [3] conducted a comparative assessment of the effect of betamethasone solution at the dose of $0.1 \mathrm{mg} / \mathrm{kg}$ in an experimentally simulated cartilage damage and described negative changes in joint structures such as thinning of the articular cartilage, disruption of the cellular hierarchy and phenotype of chondrocytes, thinning of the subchondral bone lamina propria. However, thereby, betamethasone had some inhibitive effect on the degradation of the articular cartilage in comparison with the control group, apparently due to a more rapid change in the synthetic activity of chondrocytes. There was a decrease in pathological angiogenesis due to inhibition of vascular endothelial growth factor.

D. Davis et al [4] studied chondrocytes after 30 minutes of exposure to $0.2,0.6,1,3$, and $6 \mathrm{mg} / \mathrm{ml}$ solutions of BNP and BA without benzalkonium chloride (a preservative agent used in clinical 
combined preparations of betamethasone) and did not reveal significant cell death in all groups, even on the 7th day of the observation. Thereby, the authors found a pronounced cell death of chondrocytes when exposed to the minimum dosage of benzalkonium chloride $(0.01 \mathrm{mg} / \mathrm{ml})$, which may explain scattered results of in vivo studies.
Special recommendations for the use of betamethasone and its possible side effects motivated us to conduct an experiment to study its effect on the articular elements by its frequent use.

Purpose Evaluation of the effect of several weekly intra-articular protocols of betamethasone administration on histological preparations of rabbit's knee joints.

\section{MATERIAL AND METHODS}

Fifteen adult rabbits of the Gray Giant breed, males and females, weighing 2,950-3,300 g (average 3,200 g) were divided into three main groups of 5 animals each. The first group received a single injection of betamethasone into the right knee joint. The animals of the second group received three intra-articular injection of the drug and the third one six times per week. The left knee joints of the animals were intact and were used for comparison group.

The animals were kept in cages adequate for this species and received organic food. The study complies with international and national regulations for the handling of laboratory animals.

Disposable gloves, needles, and 1-ml syringes with $0.1 \mathrm{ml}$ grading were used in the experiment. After preliminary shaving, the skin of the rabbit's right knee joint was treated with $70 \%$ alcoholic chlorhexidine solution. Then an intra-articular injection was performed. The dosage of the drug for administration to rabbits was proportional $(1 / 20)$ used for intra-articular injection in the knee joints of a human with an average weight of $65 \mathrm{~kg}$. Each vial of the drug containing $1 \mathrm{ml}$ of a solution consisting of betamethasone dipropionate and betamethasone disodium phosphate was diluted in $9 \mathrm{ml}$ of $0.9 \%$ saline solution. From the resulting solution, $0.5 \mathrm{ml}(0.25 \mathrm{mg}$ of dipropionate and $0.1 \mathrm{mg}$ of phosphate) were used for administration, which corresponds to $1 / 20$ of the dose used for intra-articular injections into the human knee joints. Injections were administered weekly according to the schedule assigned to each study group.

All rabbits were euthanized 7 days after the last corresponding administration of the drug in the group. The animals were first anesthetized with $100 \mathrm{mg} / \mathrm{kg}$ of ketamine and $8 \mathrm{mg} / \mathrm{kg}$ of xylazine intramuscularly, and then intra-cardiac injection of $10 \mathrm{ml}$ of a $19.1 \%$ potassium chloride solution was performed.

The histological material was prepared according to the technique developed for bone tissue $[5,6]$. The material was first fixed in $10 \%$ neutral formalin, followed by rinsing in running tap water for 24 hours and decalcification in a mixture of $100 \mathrm{ml}$ of $90 \%$ formic acid, $80 \mathrm{ml}$ of $40 \%$ hydrochloric acid and $820 \mathrm{ml}$ of tap water. The fluid was changed every 48 hours. Decalcification lasted 10-15 days on average. After rinsing for 24 hours in tap water, the material was dehydrated in alcohols of increasing concentrations, $70 \%$ (3 portions), $96 \%$ (two portions), $100 \%$ (one portion), where they were kept for one day in each portion.

Dehydrated samples were sequentially immerged in a solution of alcohol and chloroform 1:1 (3-5 hours), two portions of chloroform ( 1 hour each) and placed in a thermostat at $37^{\circ} \mathrm{C}$ in a mixture of chloroform and paraffin 1: 1 ( $2-3$ hours). Then, in a thermostat at $56{ }^{\circ} \mathrm{C}$, the material was soaked in two portions of paraffin ( 1 hour in the first and 24 hours in the second).

At the end of the processing, they were embedded in paraffin, cooled, and sections with a thickness of 7-10 $\mu \mathrm{m}$ were made using a Leica SM 2000R microtome. Histological sections were stained with hematoxylin and eosin, as well as picrofuchsin according to van Gieson.

Histological preparations were examined microscopically by an experienced histologist using an Axioscop-Zeiss AG microscope. To determine the areas of the structural components of the joint, a morphometric mesh of a random step by S.B. Stefanov was used [7]. The mesh was applied directly to the micropreparation and under low magnification (eyepiece $\times 7$, objective $\times 10$ ), the number of its intersections was counted for each of the studied structures: subchondral bone, cartilage, synovial membrane, and articular cavity. The position of the mesh on the histological section was randomly changed several times, each time the counting was repeated. The total number of calculated mesh crossings obtained for the entire section was taken as $100 \%$. Then, the number of mesh crossings for each of the studied structures was converted into percentages, respectively. The data obtained were processed statistically with the calculation of the Student's criterion and the $p$ value [7].

\section{RESULTS}

Microscopic examination of histological (comparison group) showed no changes in the preparations of intact left knee joints of animals morphological components of the joint, which 
indicates a normal histological structure. Normally, the articular cartilage is classified as hyaline cartilage and consists of three layers: superficial (tangential zone), intermediate (intermediate zone), and deep (radial zone). There are no blood and lymph vessels in the cartilaginous lining of the joint. The surface of the articular cartilage is flat, smooth, without any bulges or irregularities. The tangential zone is represented by a cell-free plate and flattened chondrocytes. In the intermediate zone there are rounded chondrocytes and isogenic groups of chondrocytes. The radial zone is composed of chondrocyte bands, a layer of hypertrophied (dystrophically altered) chondrocytes and a boundary line (area of mineralization). Below, directly above the bone, is the calcified hyaline cartilage (Fig. 1A).

The subchondral bone is predominantly compact with areas of cancellous structure (Fig. 1B).

The articular capsule (bag) consists of two layers, the outer one (fibrous) connected with the periosteum (Fig. 1C), and the inner one (synovium). The latter consists of the synovial intima (synoviocytes, flat synovial cells) and the subintimal fibrovascular layer with a large number of blood vessels and inclusions of adipose tissue (Fig. 1D). The surface of the synovial membrane is smooth with the villi (Fig. 1E). At the junction with the cartilaginous lining (transition zone), synovial cells are gradually replaced by chondrocytes. The proportion of the area of the studied structures from the total area of the histological section is presented in Table 1 .

In the group of rabbits with a single injection of betamethasone, no significant changes in the knee joint were observed either. The normal structure of the articular capsule remained unchanged with the outer fibrous layer and the inner one, represented by the synovial membrane. The surface of the synovial membrane was smooth, with the presence of villi, and lined with flat synoviocytes (Fig. 1F). Three morphological types were identified in the corresponding areas of the articular capsule: fibrous, areolar, and fatty (Fig. $1 \mathrm{G}, \mathrm{H}, \mathrm{I}$ ). The phenomena of dystrophy and necrosis were observed at $1.56 \pm 0.32 \%$ of the total area of the histological section $(\mathrm{p}<0.05)$. The subchondral bone was practically intact in all cases $(1.14 \pm 0.75 \%, p<0.001)$.

In the group of animals with three doses of the drug, there were changes that captured all the structural components of the joint. Normal histological structure was detected only in some areas (Fig. 2A). In most cases, the articular surface of the cartilage had an uneven lining with defects formed due to foci of necrosis and destruction, which sometimes alternated with areas of cartilage tissue proliferation. The area of dystrophy and necrosis was $10.05 \pm 0.75 \%$ greater $(p<0.05)$ compared with the group of a single injection. In the presence of a significant lesion of the cartilage, the subchondral bone was frequently involved in the process (Fig. 2B). In addition, there were foci of necrosis, destruction and lysis of bone trabeculae in the underlying bone (Fig. 2 C, D). The area of dystrophy and necrosis in the subchondral bone was $8.11 \pm 0.5 \%$ greater $(p<0.001)$ compared with the previous group,

The synovium was thickened and swollen. There was marked plethora of her vessels and perivascular edema (Fig. 2E). In some cases, foci of destruction of the synovial membrane were seen (Fig. $2 \mathrm{~F}$ ) with an area greater by $6.25 \pm 0.32 \%$ than in the group with a single injection $(\mathrm{p}<0.05)$.

Table 1

Areas of structural components in the intact knee joints and joints with injections of betametazone (diprospan)

( $\%$ from the total area of the histological section, $\mathrm{M} \pm \mathrm{m}(95 \% \mathrm{CI})$ )

\begin{tabular}{|c|c|c|c|c|c|c|c|}
\hline & $\begin{array}{l}\text { Unchanged } \\
\text { subchondral } \\
\text { bone }\end{array}$ & $\begin{array}{l}\text { Subchondral } \\
\text { bone with } \\
\text { dystrophy and } \\
\text { necrosis }\end{array}$ & $\begin{array}{l}\text { Unchanged } \\
\text { articular } \\
\text { cartilage }\end{array}$ & $\begin{array}{c}\text { Articular } \\
\text { cartilage with } \\
\text { dystrophy and } \\
\text { necrosis }\end{array}$ & $\begin{array}{l}\text { Unchanged } \\
\text { synovial } \\
\text { membrane }\end{array}$ & \begin{tabular}{|c|} 
Synovial \\
membrame with \\
dystrophy and \\
necrosis \\
\end{tabular} & Joint Cavity \\
\hline & $39.86 \pm 0.09$ & 0 & $29.96 \pm 0.13$ & 0 & $20.14 \pm 0.21$ & 0 & $10.05 \pm 0.02$ \\
\hline $\begin{array}{l}\text { After a single } \\
\text { injection of } \\
\text { dipropan }\end{array}$ & $\begin{array}{r}39.34 \pm 0 \\
(95 \% \mathrm{CI} \\
-0.2\end{array}$ & 0 & $\begin{array}{l}08^{* * *} \\
-0.78 ; \\
7)\end{array}$ & $\begin{array}{r}1.14 \pm 0 . \\
(95 \% \mathrm{CI} \\
1.33\end{array}$ & $\begin{array}{r}19.12 \pm 0 \\
(95 \% \mathrm{C} \\
-0.6 \\
\end{array}$ & $\begin{array}{c}1.56 \pm 0.24 * * \\
(95 \% \text { CI } 1.31 \\
1.81)\end{array}$ & $\begin{array}{c}9.50 \pm 0.26^{* *} \\
(95 \% \text { CI }-0.81 \\
-0.28)\end{array}$ \\
\hline $\begin{array}{l}\text { After } 3 \\
\text { injections of } \\
\text { diprospan }\end{array}$ & $\begin{array}{c}27.98 \pm 3.70 * * * \\
(95 \% \text { CI }-15.19 \\
-7.55)\end{array}$ & $\begin{array}{c}8.11 \pm 0.47 * * * \\
(95 \% \text { CI } 7.63 ; \\
8.59)\end{array}$ & $\begin{array}{c}21.78 \pm 0.75^{* *} \\
(95 \% \text { CI }-8.33 ; \\
-6.77)\end{array}$ & $\begin{array}{c}10.05 \pm 1.71 * * \\
(95 \% \text { CI } 7.15 \\
10.69)\end{array}$ & $\begin{array}{c}14.62 \pm 1.39 * * \\
(95 \% \text { CI }-5.96 \\
-3.04)\end{array}$ & $\begin{array}{c}7.81 \pm 0.61 * * \\
(95 \% \text { CI 5.57; } \\
6.93)\end{array}$ & $\begin{array}{c}9.65 \pm 1.24 \\
(95 \% \text { CI }-1.16 ; \\
1.46)\end{array}$ \\
\hline $\begin{array}{l}\text { After } 6 \\
\text { injections of } \\
\text { diprospan }\end{array}$ & $\begin{array}{c}21.27 \pm 1.38 * * \\
(95 \% \text { CI }-10.78 ; \\
-2.64)\end{array}$ & $\begin{array}{c}19.29 \pm 1.50^{* * *} \\
(95 \% \text { CI } 9.56 ; \\
12.80)\end{array}$ & $\begin{array}{c}8.17 \pm 0.58 * * * \\
(95 \% \text { CI }-14.59 ; \\
-12.63)\end{array}$ & $\begin{array}{c}16.44 \pm 1.61 * * * \\
(95 \% \text { CI } 3.97 ; \\
8.81)\end{array}$ & $\begin{array}{c}7.87 \pm 0.40 * * * \\
(95 \% \mathrm{CI}-8.24 ; \\
-5.25)\end{array}$ & $\begin{array}{c}13.93 \pm 0.75^{* * *} \\
(95 \% \text { CI } 5.12 \\
7.12)\end{array}$ & $\begin{array}{c}13.02 \pm 3.1 \\
(95 \% \text { CI }-0.09 ; \\
6.82)\end{array}$ \\
\hline
\end{tabular}

Notes $95 \%$ CI - $95 \%$ confidence interval for difference; $p$ and $95 \%$ confidence interval shown for comparison with the указаны для сравнения с предыдущей группой (с меньшим количеством инъекций); ${ }^{*}-\mathrm{p}<0,05,{ }^{* *}-\mathrm{p}<0,01,{ }^{* * *}-\mathrm{p}<0,001$ 

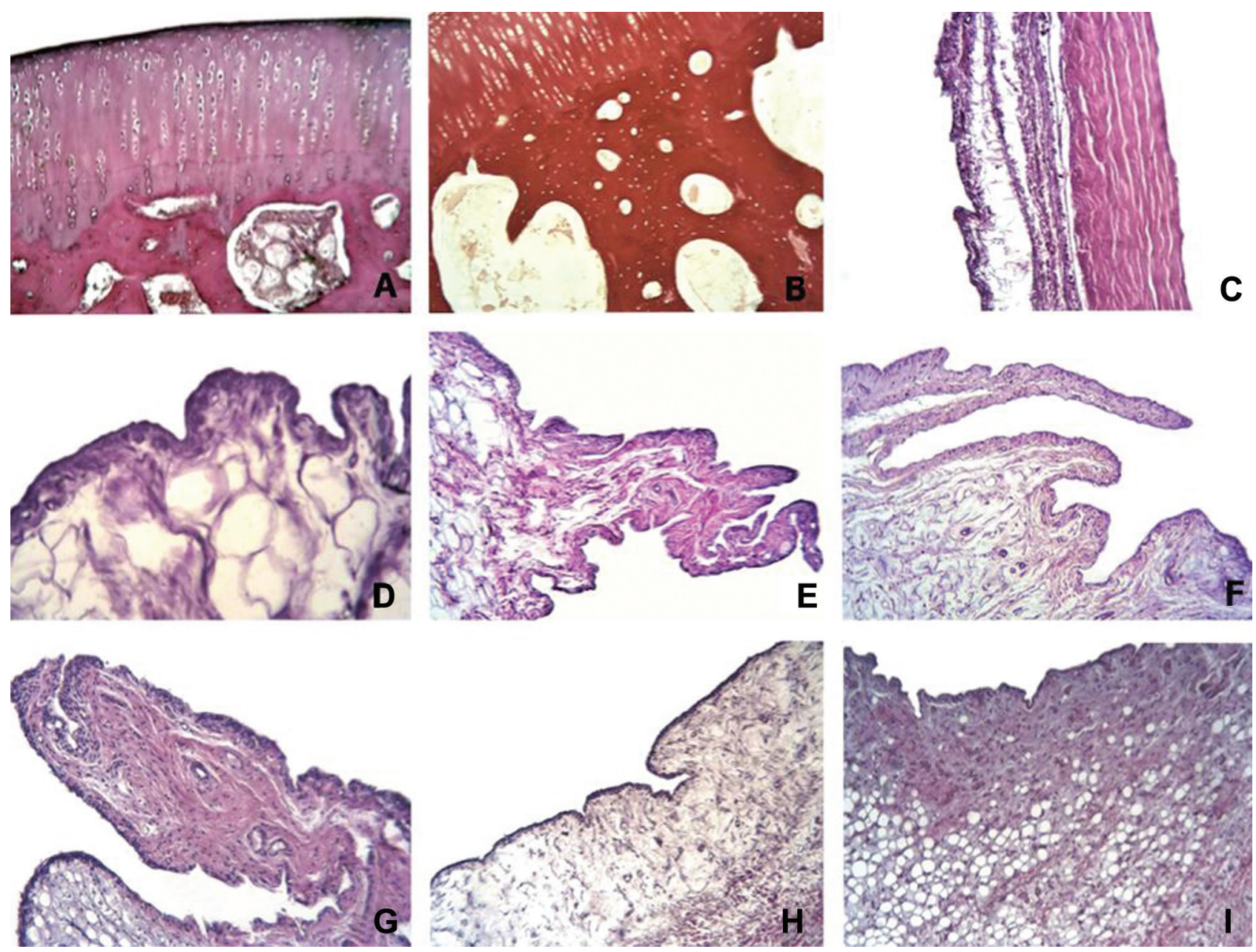

Fig. 1 The histological structure of the joint after a single injection of betamethasone: $\boldsymbol{A}$ normal histological structure of the articular cartilage; ${ }^{b}$ subchondral compact bone of the joint with areas of spongy structure; $\boldsymbol{C}$ outer fibrous layer of the articular capsule; $\boldsymbol{D}$ unchanged synovial membrane; $\boldsymbol{E}$ villi of the synovial membrane; $\boldsymbol{F}$ normal histological structure of the synovium and its villi; $\boldsymbol{G}$ synovial membrane of the fibrous type; $\boldsymbol{H}$ areolar type synovium; $\boldsymbol{I}$ fatty type synovium; $\boldsymbol{A}, \boldsymbol{C}, \boldsymbol{E}, \boldsymbol{F}, \boldsymbol{G}, \boldsymbol{H}, \boldsymbol{I}$ staining with hematoxylin and eosin $\times 200 ; \boldsymbol{B}$ staining according to van Gieson, $\times 200 ; \boldsymbol{D}$ staining with hematoxylin and eosin $\times 400$
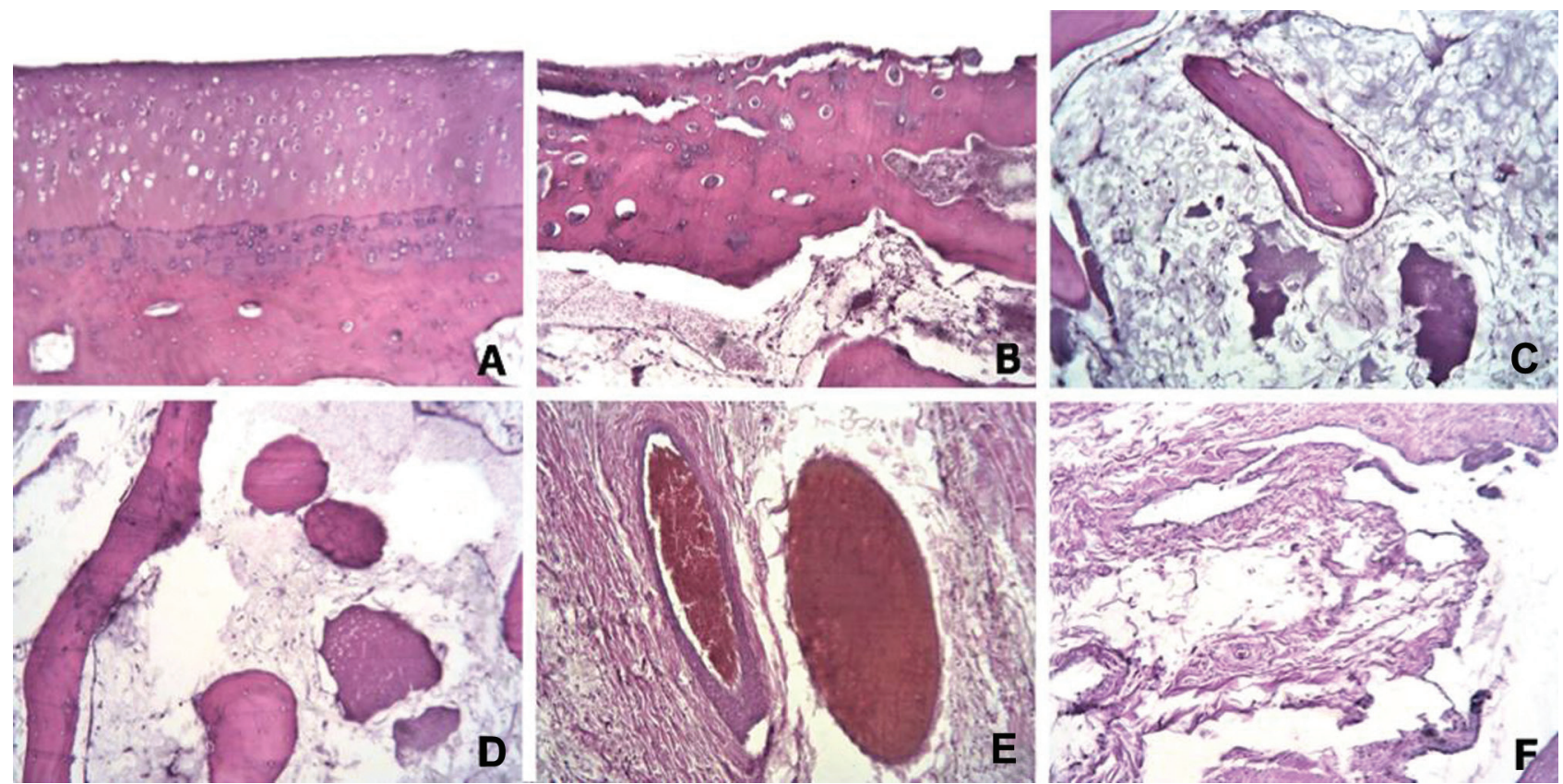

Fig. 2 Changes in the structural components of the joint after triple administration of betamethasone: $\boldsymbol{A}$ preservation of the normal histological structure in a separate site of the joint; $\boldsymbol{B}$ destruction of articular cartilage with the involvement of the subchondral bone; $\boldsymbol{C}$ necrosis, destruction and lysis of bone trabeculae in the subchondral bone; $\boldsymbol{D}$ necrosis, destruction and lysis of bone trabeculae in the subchondral bone; $\boldsymbol{E}$ vascular congestion and perivascular edema of the synovium; $\boldsymbol{F}$ focus of destruction of the synovium. Hematoxylin and eosin staining, $\times 200$ 
It is important to note that in the second group, no inflammatory cellular infiltration of the joint structures was detected in any cases, which indicates the aseptic nature of necrotic changes.

Morphological changes in the third group with six injections of betamethasone were more pronounced. Structural changes were observed in each of the layers. Only isolated structures of the knee joints remained unchanged (Fig. 3A).

The articular cartilage was subject to necrosis in all the cases, and its layers were not identified (Fig. 3B). The area of necrotic changes was by $6.39 \pm 0.75 \%$ greater than in the group with three doses $(\mathrm{p}<0.001)$.
There were areas of destruction of varying severity (Fig. 3C), frequently with deep penetration into the underlying bone. In the latter, extensive necrotic areas with destruction and lysis of bone tissue were also found (Fig. 3D), greater by $11.18 \pm 0.5 \%$ than in the previous group $(\mathrm{p}<0.001)$.

The synovium contained not only separate areas of destruction but was also prone to necrosis involving whole villi (Fig. 3E), by $6.12 \pm 0.32 \%$ larger area than after triple injection $(\mathrm{p}<0.001)$.

Similar to the second group, there was no inflammatory cell infiltration into the structural components of the joint.
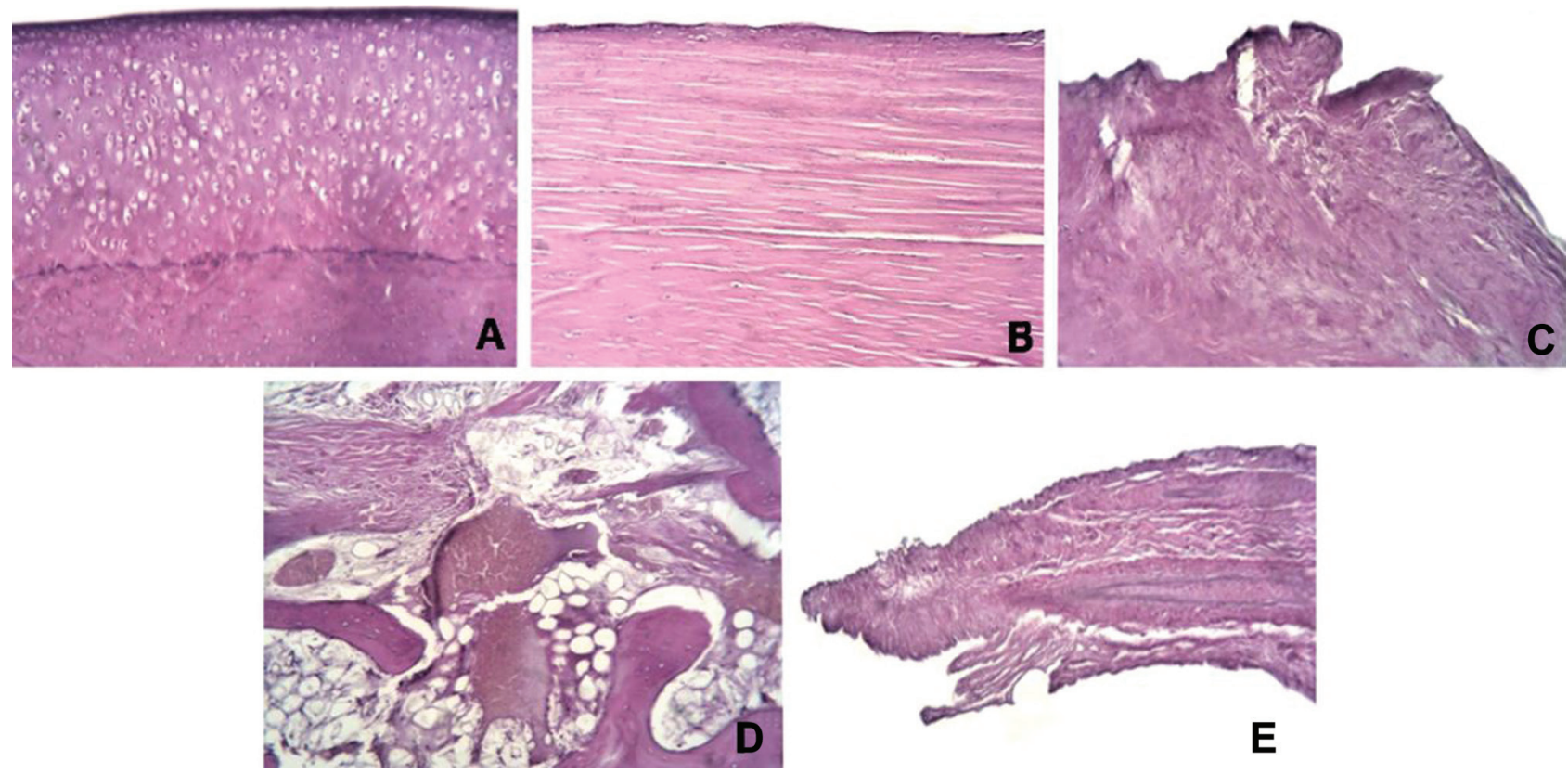

Fig. 3 Morphological changes in the joint after six injections of betamethasone: $\boldsymbol{A}$ unchanged separate fragment of the joint. Structural changes in each of the layers with the preservation of the histological structure only in isolated areas; $\boldsymbol{B}$ total necrosis of the articular cartilage; $\boldsymbol{C}$ destruction of the surface of the necrotic articular cartilage; $\boldsymbol{D}$ extensive necrotic area in the subchondral bone with destruction and lysis of bone trabeculae; $\boldsymbol{E}$ necrosis of the villus of the synovium. Hematoxylin and eosin staining, $\times 200$

\section{DISCUSSION}

Our study found a direct correlation between the number of weekly intra-articular injections of the drug and the severity of destruction in the articular structures. There is reason to believe that multiple intra-articular injections of betamethasone with a short interval between them lead to degenerative and necrotic changes in all morphological components of the joint with their subsequent destruction. At the same time, the absence of inflammatory cell infiltration confirms that tissue necrosis is aseptic in nature.

Previous in vivo studies demonstrated a dosedependent effect of GCS on the articular cartilage. So, A.M. Lutfi et al. [8] in 1978 observed a progressive damage to the articular cartilage at 10 and 20 weeks after 10 intra-articular injections of the combined betamethasone drug ( $3 \mathrm{mg}$ BNP and $3 \mathrm{mg}$ BA with $0.2 \mathrm{mg}$ benzalkonium) for 20 weeks. M.B. Albano et al. [9] showed a dose-dependent decrease in the concentration of proteoglycans of the articular cartilage resulting from multiple injections of betamethasone ( 6 and 8 injections with a total dose of $>2.1 \mathrm{mg}$ ). Most publications report that low dosages $(<2.1 \mathrm{mg})$ of betamethasone did not cause significant cartilage damage or cell death while chondrotoxicity, loss of cartilage proteins, and progressive damage were observed at higher dosages $(>2.1 \mathrm{mg})$. However, there is also evidence of a negative effect on the viability of chondrocytes, even with a single injection of $1 \mathrm{mg}$ of betamethasone [2]. 
In our study, the dose of betamethasone in proportionally diluted saline with a single administration was $0.35 \mathrm{mg}(0.25 \mathrm{mg}$ of dipropionate and $0.1 \mathrm{mg}$ of phosphate), therefore, only doses of betamethasone more than $1 \mathrm{mg}$ led to negative effects on the structure of the articular cartilage and synovium.

A limitation of our study was that we did not have a control comparison group with induced OA. According to studies, the effect of GCS on a healthy joint and a joint affected by $\mathrm{OA}$ is different. The consequences of using GCS for the structure of articular cartilage depend on the underlying disease and the phenotypic characteristics of chondrocytes. OA is accompanied by phenotypic switching of chondrocytes due to the activation of signaling pathways induced by mechanical stress and inflammation. Under their influence, the chondrocytes acquire the phenotype of hypertrophied cells of the growth plate with renewed proliferation and hypertrophic differentiation. Thereby, there is a stimulation of the degeneration and synthesis of the matrix under the influence of various inflammatory mediators, what is accompanied by the predominance of catabolic processes leading to the loss of the matrix $[10,11]$.

In addition, such phenotypic switching of chondrocyte and associated cartilage degeneration are additionally stimulated by secondary inflammatory processes in the synovial membrane and subchondral bone, also contributing to the progression of OA [12-15].

In vitro studies confirm that the main pharmacological effects of corticosteroids on cartilage matrix homeostasis may be classified as anti-anabolic and anti-catabolic, with anti-catabolic effects occurring at lower concentrations than those affecting matrix synthesis [16]. In healthy cartilage, the rate of matrix renewal is low and catabolic processes are not activated, despite the fact that they play a role in normal cartilage remodeling. In vivo animal studies in the absence of joint inflammation or instability show that in the normal remodeling process anti-anabolic effects of corticosteroids, such as suppression of collagen II synthesis, dominate, leading to progressive matrix degeneration, which is dose- and time-dependent [8, 9, 17-22].

In OA, corticosteroids suppress matrix degeneration by directly inhibiting enhanced catabolic processes (such as increased expression of matrix metalloproteinase) and indirectly through multiple antiinflammatory effects that interfere with the phenotypic changes in chondrocytes caused by inflammation [16]. There are studies conducted on OA models in various animal species that confirm the chondroprotective effect of corticosteroids in the context of OA as a result of a decrease in structural damage to the joint with restoration of matrix biosynthesis and a decrease in proteoglycan loss [23-28].

Thus, the effect of corticosteroids on the integrity of the cartilage matrix depends on the context. Chondroprotective effects are observed in the inflammatory OA environment where chondrocytes have undergone an inflammation-mediated phenotypic change, and matrix remodeling is enhanced and shifted towards degradation. In the normal healthy cartilage with a balanced matrix remodeling and a standard chondrocyte phenotype, the anti-anabolic effects of corticosteroids may lead to chondrotoxicity [29].

\section{COCLUSIONS}

A single intra-articular injection of diprospan does not significantly disrupt the morphological structure of the knee joint. Three doses of the drug lead to degenerative and necrotic changes in all structural components of the joint $(p<0.05)$. They are significantly aggravated by administration of six doses which result in its pronounced destruction $(p<0.001)$. Necrosis is aseptic in nature, since inflammatory cell infiltration is absent in all cases.

The use of betamethasone is effective and safe if the therapeutic dose is accurately calculated and the frequency and duration of treatment is observed: the treatment period should be as short as possible with a moderate frequency of administration. The question of how much of the drug and how often to inject it into joints of various sizes remains relevant. There are some general guidelines of the relationship between joint size and the amount of the drug administered, but these require further study in large randomized trials.

Based on the results of our study, intra-articular administration of betamethasone with a short (less than 2-3 weeks) interval between injections cannot be recommended.

\section{REFERENCES}

1. Farkas B., Kvell K., Czömpöly T., Illés T., Bárdos T. Increased chondrocyte death after steroid and local anesthetic combination. Clin. Orthop. Relat. Res., 2010, vol. 468, no. 11, pp. 3112-3120. DOI: 10.1007/s11999-010-1443-0

2. Dragoo J.L., Danial C.M., Braun H.J., Pouliot M.A., Kim H.J. The chondrotoxicity of single-dose corticosteroids. Knee Surg. Sports Traumatol. Arthrosc., 2012, vol. 20, no. 9, pp. 1809-1814. DOI: 10.1007/s00167-011-1820-6 
3. Kabalyk M.A., Nevzorova V.A., Dubov V.S., Tsygankov M.A., Kovalenko T.S. Molekuliarnye i kletochnye effekty vnutrisustavnogo vvedeniia betametazona pri eksperimentalnom osteoartrite [Molecular and cellular effects of intraarticular injection of betamethasone in experimental osteoarthritis]. Genij Ortopedii, 2020, vol. 26, no. 1, pp. 65-71. DOI: 10.18019/1028-4427-2020-26-1-65-71 (in Russian)

4. Davis D., Cyriac M., Ge D., You Z., Savoie F.H. In vitro cytotoxic effects of benzalkonium chloride in corticosteroid injection suspension. J. Bone Joint Surg. Am., 2010, vol. 92, no. 1, pp. 129-137. DOI: 10.2106/JBJS.H.01561

5. Korzhevskii D.E. Kratkoe izlozhenie osnov gistologicheskoi tekhniki dlia vrachei i laborantov-gistologov [Summary of histological technique basics for physicians and histology technicians]. SPb., Kroft, 2005, 48 p. (in Russian)

6. Pakht A.V., Manizer N.M. Osobennosti obrabotki kostnoi tkani [Special characteristics of bone tissue processing]. Biblioteka Patologoanatoma, 2008. Issue 89: Izbrannye voprosy patologoanatomicheskoi tekhniki [Selected questions of the pathoanatomical technique], pp. 6-11. (in Russian)

7. Stefanov S.B. Morfometricheskaia setka sluchainogo shaga kak sredstvo uskorennogo izmereniia elementov morfogeneza [Morphometric grid of a random step as a means of accelerated measurement of morphogenesis elements]. Tsitologiia, 1974, vol. 16, no. 6, pp. 785-787. (in Russian)

8. Lutfi A.M., Kosel K. Effects of intra-articularly administered corticosteroids and salicylates on the surface structure of articular cartilage. J. Anat., 1978, vol. 127, pt. 2, pp. 393-402.

9. Albano M.B., Skroch G.P., Ioshii S.O., Grahels X.S., de Alencar P.G., Matias J.E. Computerized photocolorimetric analysis of the effects of intraarticular betamethasone on the proteoglycan concentration of leporine knee cartilage matrix: influence of the number of intraarticular injections. Rev. Col. Bras. Cir., 2009, vol. 36, no. 3, pp. 256-260.

10. Cecil D.L., Johnson K., Rediske J., Lotz M., Schmidt A.M., Terkeltaub R. Inflammation-induced chondrocyte hypertrophy is driven by receptor for advanced glycation end products. J. Immunol., 2005, vol. 175, no. 12, pp. 8296-8302. DOI: 10.4049/jimmunol.175.12.8296

11. Pitsillides A.A., Beier F. Cartilage biology in osteoarthritis - lessons from developmental biology. Nat. Rev. Rheumatol., 2011, vol. 7, no. 11, pp. 654-663. DOI: 10.1038/nrrheum.2011.129

12. Martel-Pelletier J., Pelletier J.P. New insights into the major pathophysiological processes responsible for the development of osteoarthritis. Semin. Arthritis Rheum., 2005, vol. 34, no. 6, Suppl. 2, pp. 6-8. DOI: 10.1016/j.semarthrit.2004.03.003

13. Loeser R.F. Aging processes and the development of osteoarthritis. Curr. Opin. Rheumatol., 2013, vol. 25, no. 1, pp. 108-113. DOI: 10.1097/ BOR.0b013e32835a9428

14. Samuels J., Krasnokutsky S., Abramson S.B. Osteoarthritis: a tale of three tissues. Bull. NYU Hosp. Jt. Dis., 2008, vol. 66, no. 3, pp. 244-250.

15. Scanzello C.R. Pathologic and pathogenic processes in osteoarthritis: the effects of synovitis. HSS J., 2012, vol. 8, no. 1, pp. 20-22. DOI: 10.1007/ s11420-011-9228-x

16. Richardson D.W., Dodge G.R. Dose-dependent effects of corticosteroids on the expression of matrix-related genes in normal and cytokine-treated articular chondrocytes. Inflamm. Res., 2003, vol. 52, no. 1, pp. 39-49. DOI: 10.1007/s000110300012

17. Ishikawa K. Effect of intra-articular corticosteroid on the meniscus. A histological and histochemical study in rabbit knees. J. Bone Joint Surg. Am., 1981, vol. 63, no. 1, pp. 120-130.

18. Behrens F., Shepard N., Mitchell N. Alterations of rabbit articular cartilage by intra-articular injections of glucocorticoids. J. Bone Joint Surg. Am., 1975, vol. 57, no. 1, pp. 70-76.

19. Chunekamrai S., Krook L.P., Lust G., Maylin G.A. Changes in articular cartilage after intra-articular injections of methylprednisolone acetate in horses. Am. J. Vet. Res., 1989, vol. 50, no. 10, pp. 1733-1741.

20. Mankin H.J., Conger K.A. The acute effects of intra-articular hydrocortisone on articular cartilage in rabbits. J. Bone Joint Surg. Am., 1966, vol. 48, no. 7 , pp. 1383-1388.

21. Murray R.C., DeBowes R.M., Gaughan E.M., Zhu C.F., Athanasiou K.A. The effects of intra-articular methylprednisolone and exercise on the mechanical properties of articular cartilage in the horse. Osteoarthritis Cartilage, 1998, vol. 6, no. 2, pp. 106-114. DOI: 10.1053/joca.1997.0100

22. Salter R.B., Gross A., Hall J.H. Hydrocortisone arthropathy - an experimental investigation. Can. Med. Assoc. J., 1967, vol. 97, no. 8, pp. $374-377$.

23. Pelletier J.P., Martel-Pelletier J. Protective effects of corticosteroids on cartilage lesions and osteophyte formation in the Pond-Nuki dog model of osteoarthritis. Arthritis Rheum., 1989, vol. 32, no. 2, pp. 181-193. DOI: 10.1002/anr.1780320211

24. Pelletier J.P., Mineau F., Raynauld J.P., Woessner J.F. Jr, Gunja-Smith Z., Martel-Pelletier J. Intraarticular injections with methylprednisolone acetate reduce osteoarthritic lesions in parallel with chondrocyte stromelysin synthesis in experimental osteoarthritis. Arthritis Rheum., 1994, vol. 37, no. 3, pp. 414-423. DOI: 10.1002/art.1780370316

25. Pelletier J.P., DiBattista J.A., Raynauld J.P., Wilhelm S., Martel-Pelletier J. The in vivo effects of intraarticular corticosteroid injections on cartilage lesions, stromelysin, interleukin-1, and oncogene protein synthesis in experimental osteoarthritis. Lab. Invest., 1995, vol. 72, no. 5, pp. 578-586.

26. Huebner K.D., Shrive N.G., Frank C.B. Dexamethasone inhibits inflammation and cartilage damage in a new model of post-traumatic osteoarthritis. J. Orthop. Res., 2014, vol. 32, no. 4, pp. 566-572. DOI: 10.1002/jor.22568

27. Zhang Z., Wei X., Gao J., Zhao Y., Zhao Y., Guo L., Chen C., Duan Z., Li P., Wei L. Intra-articular injection of cross-linked hyaluronic aciddexamethasone hydrogel attenuates osteoarthritis: an experimental study in a rat model of osteoarthritis. Int. J. Mol. Sci., 2016, vol. 17, no. 4, pp. 411. DOI: 10.3390/ijms17040411

28. Lu Y.C., Evans C.H., Grodzinsky A.J. Effects of short-term glucocorticoid treatment on changes in cartilage matrix degradation and chondrocyte gene expression induced by mechanical injury and inflammatory cytokines. Arthritis Res. Ther., 2011, vol. 13, no. 5, pp. R142. DOI: 10.1186/ar3456

29. Bodick N., Williamson T., Strand V., Senter B., Kelley S., Boyce R., Lightfoot-Dunn R. Local effects following single and repeat intra-articular injections of triamcinolone acetonide extended-release: results from three nonclinical toxicity studies in dogs. Rheumatol. Ther., 2018, vol. 5, no. 2, pp. 475-498. DOI: $10.1007 / \mathrm{s} 40744-018-0125-3$

Received: 07.05.2020

\section{Information about the authors:}

\section{Ainur N. Nuriakhmetov,}

Kazan State Medical University, Kazan, Russian Federation, Republican Clinical Hospital, Kazan, Russian Federation,

Email: jouric@yandex.ru

2. Ildar F. Akhtiamov, M.D., Ph.D., Professor,

Kazan State Medical University, Kazan, Russian Federation, Email: yalta60@mail.ru

3. Dmitry E. Tsyplakov, M.D., Ph.D., Professor,

Kazan State Medical University, Kazan, Russian Federation, Email: dr.allakazan@yandex.ru

4. Al M. Abdullah,

Kazan State Medical University, Kazan, Russian Federation,

Email:munnarussia@gmail.com

5. Tatyana Yu. Nuriakhmetova,

Kazan State Medical University, Kazan, Russian Federation,

Email: tatiananuriakhmetova@gmail.com 